\title{
Proposta de indicadores para avaliação de desempenho dos Sistemas de Gestão Ambiental e de Segurança e Saúde no Trabalho de Empresas do ramo de engenharia consultiva
}

\author{
Proposed indicators for performance evaluation of Environmental \\ Management System and Occupational Health and Safety Management \\ Systems of a consulting engineering company
}

\author{
Clarissa Lima Almeida ${ }^{1}$ \\ Ana Bárbara de Araújo Nunes ${ }^{1}$
}

\begin{abstract}
Resumo: O processo de implantação de um sistema de gestão agrega valor à cultura organizacional, pois desenvolve competências relacionadas ao planejamento e execução das atividades, prioriza a capacidade de trabalho em equipe e promove a confiabilidade do sistema produtivo. Deste modo, uma das principais ferramentas utilizadas na política econômica das organizações tem sido a implementação de um Sistema de Gestão Ambiental (SGA). Do mesmo modo, o crescente número de acidentes repercutidos na mídia fez com que as organizações buscassem nos Sistemas de Gestão de Segurança e Saúde no Trabalho (SGSST) o instrumento para alcançar melhores resultados na área de SST. O uso dos indicadores de avaliação de desempenho auxilia as organizações a quantificar e relatar o desempenho de seus sistemas de gestão. Diante disso, o objetivo deste trabalho foi propor um conjunto de indicadores de avaliação de desempenho para os SGA e SGSST de uma empresa certificada pelas normas NBR ISO 14001:2004 e OHSAS 18001:2007, a fim de melhorar o desempenho destes sistemas, contribuindo com seus processos de melhoria contínua. Para isso, foi realizado um estudo de caso em uma empresa de engenharia consultiva, em que foram levantados os dados necessários para viabilizar a elaboração e proposta dos indicadores, por meio, principalmente, de entrevistas, aplicação de questionário aos funcionários e acompanhamento às auditorias realizadas na empresa. Desta forma, foram propostos 23 indicadores, sendo 11 para o SGA e 12 para o SGSST. Os indicadores propostos podem ser empregados em SGA e SGSST de empresas de qualquer ramo de atividade, por se tratar de indicadores de fácil implementação e controle.
\end{abstract}

Palavras-chave: ISO 14001. OHSAS 18001. Indicadores de avaliação de desempenho.

\begin{abstract}
The process of implementing a management system adds value to the organizational culture, because it develops skills related to activity planning and execution; prioritizes teamwork ability; and promotes the reliability of the production system. Thus, one of the main tools employed by the economic policy of organizations has been the implementation of an Environmental Management System (EMS). Moreover, the growing number of accidents broadcast by the media has made organizations seek, in the Occupational Health and Safety Management Systems (OHSMS), an instrument to achieve better results in the field of OSH. The use of indicators of performance evaluation helps organizations quantify and report the performance of their management systems. Therefore, the aim of this study was to propose a set of performance evaluation indicators for the EMS and OHSMS of a NBR ISO 14001:2004 and OHSAS 18001:2007 certified company in order to improve the performance of these systems, contributing to their continuous improvement processes. To this end, a case study was conducted in a consulting engineering company, where necessary data to enable the proposal and development of these indicators was collected, mainly through the application of interviews and questionnaires to staff members and the monitoring of audits carried out in the company. Thus, 23 indicators were proposed: 11 for EMS and 12 for OHSMS. The proposed indicators can be employed in the EMS and OHSMS of companies of any sector because they can be easily implemented and controlled.
\end{abstract} Keywords: ISO 14001. OHSAS 18001. Performance evaluation indicators.

\footnotetext{
${ }^{1}$ Programa de Pós-graduação em Engenharia Civil, Universidade Federal do Ceará - UFC, Campus do Pici, s/n, Bloco 713 , CEP 60451-970, Fortaleza, CE, Brasil, e-mail: abarbara@deha.ufc.br; clarissa_lalmeida@yahoo.com.br
} 


\section{Introdução}

Muito tem sido dito nos dias atuais acerca de desenvolvimento sustentável, escassez dos recursos naturais, poluição do ar, da água e do solo, sendo que não é de agora que essa preocupação com os recursos naturais assusta os ambientalistas, profissionais, estudiosos e população em geral. Com o passar dos anos e com a rapidez do desenvolvimento tecnológico, o homem apressou-se também em buscar meios para acompanhar essa evolução, tentando conciliar o desenvolvimento tecnológico à gestão adequada dos recursos ambientais e demais questões associadas, tais como a saúde e segurança do trabalhador.

Fisher et al. (2009) comenta que as empresas perceberam que a necessidade de proteger o ambiente significa analisar sua responsabilidade do ponto de vista ambiental, reconhecer as áreas problemáticas, documentar a situação atual, além de fazer todo o esforço no sentido de obter melhorias. Para isso, não basta considerar apenas os processos produtivos, mas toda a cadeia de processos da empresa.

Quanto ao Sistema de Gestão de Segurança e Saúde no Trabalho (SGSST), este assume um papel importantíssimo no que diz respeito à consolidação de um ambiente seguro e sadio aos funcionários da organização (MENDES; SILVA; MEDEIROS, 2003). Deste modo, o trabalho deve ser projetado de modo que o homem, com suas capacidades e necessidades, seja o seu referencial, de modo que o trabalho possa ser: realizável, suportável, pertinente e conduza à satisfação (FISHER et al., 2009).

Com isso, várias iniciativas internacionais foram surgindo no intuito de se alcançar níveis de desenvolvimento compatíveis com as exigências atuais de mercado. Dentre estas, destacam-se as certificações NBR ISO 14001:2004 - Sistemas de Gestão Ambiental (SGA) e OHSAS 18001:2007 - Sistemas de Gestão de Saúde e Segurança no Trabalho (SGSST). Estas normas trazem embutidas em si uma grande preocupação mundial por melhores condições e resultados no modo como as empresas encaram os impactos que provocam ao meio ambiente e, do mesmo modo, referente à preocupação com a saúde e segurança de seus trabalhadores no ambiente de trabalho, respectivamente.

As iniciativas de implantação destas normas só serão eficazes se as empresas passarem por auditorias e possuírem indicadores que controlem os resultados e metas estipulados para a promoção da melhoria contínua destes sistemas.

As medições precisam ser decorrência das estratégias corporativas da organização, abrangendo os principais processos, bem como seus resultados. (TACHIZAWA, 2011, p. 108).

Devido a isso, surgiram diversos indicadores de desempenho dos sistemas de gestão, que vieram suprir essa necessidade de medição e verificação da eficiência dos processos, produtos e serviços das empresas.

Além disso, acredita-se que a utilização de indicadores de desempenho é de fundamental importância para o acompanhamento do desempenho dos sistemas de gestão das empresas em geral e de seus processos de melhoria contínua. Os indicadores possibilitam conhecer a real situação que se deseja modificar, além de estabelecer as prioridades, escolher os beneficiados, identificar os objetivos e traduzi-los em metas e, podendo assim, acompanhar de modo eficaz o andamento dos trabalhos, avaliar os processos, adotar os redirecionamentos necessários e verificar os resultados e impactos obtidos (SERVIÇO..., 2010). Com isso, pode-se entender o significado de Objetivo como algo mais amplo, genérico e qualitativo, como no seguinte exemplo: reduzir o consumo de papel. Enquanto a Meta é direta e quantitativa em relação ao que é esperado, tais como: Consumir $2,71 \mathrm{~kg}$ de papel por funcionário/mês.

Segundo Tachizawa $(2011$, p. 281), “[...] o que não pode ser medido não pode ser avaliado e, consequentemente, não há como decidir sobre ações a tomar". Dentro deste contexto, buscou-se estudar os indicadores de avaliação de desempenho para os SGA e SGSST, a fim de propor novos indicadores para o aprimoramento destes sistemas de gestão. Desta forma, considerando-se o crescimento do mercado das empresas de engenharia consultiva e sentindo a necessidade pela realização de trabalhos de pesquisa sobre os sistemas de gestão dessas empresas, visto que ainda são poucos os estudos encontrados na literatura nacional e internacional nessa área, decidiu-se então pela realização deste estudo.

\section{Conceituação de Sistema de Gestão Ambiental}

Segundo Dias (2011), Gestão Ambiental, do ponto de vista empresarial, é a expressão utilizada para se denominar a gestão empresarial que se orienta para evitar, na medida do possível, problemas para o meio ambiente. Em outras palavras, é a gestão cujo objetivo é conseguir que os efeitos ambientais não ultrapassem a capacidade suporte do meio em que a organização está situada, ou seja, promover o desenvolvimento sustentável.

As empresas tendem a adotar diversos procedimentos que utilizam o meio ambiente para reforçar a sua competitividade. Se o meio ambiente foi considerado inicialmente um custo assumido pelas empresas, hoje em dia, elas usam instrumentos que, ao mesmo tempo que protegem o meio ambiente, também melhoram sua eficiência. Deste modo, uma das principais ferramentas utilizadas na política econômica das organizações tem sido a implementação de um SGA (LOZANO; VALLÉS, 2007). 


\subsection{NBR ISO 14001:2004}

A principal norma de gestão ambiental da atualidade é a norma internacional ISO 14001. Ela faz parte do conjunto ISO 14000, sendo a única norma certificável dentro deste conjunto (CAMPOS; SELIG, 2002). A norma NBR ISO 14001 tem sido o instrumento mais utilizado para desenvolver a gestão ambiental nas indústrias (OLIVEIRA; SERRA, 2010).

A ISO 14001 tem por objetivo fornecer às organizações os elementos de um SGA eficaz, passível de integração com os demais objetivos da organização. Sua concepção foi idealizada de forma a aplicar-se a todos os tipos e partes de organizações, independente de suas condições geográficas, culturais e sociais (DONAIRE, 2008).

O modelo de gestão adotado pela norma NBR ISO 14001:2004 foi baseado no ciclo PDCA, que recebeu esse nome devido às iniciais retiradas das palavras inglesas (Plan-Do-Check-Act) Planejar-Implementar-Checar-Agir).

Convém salientar que a norma NBR ISO 14001 não coloca requisitos absolutos ao desempenho ambiental da empresa, exceto a obrigação de cumprir a legislação e prescrições aplicáveis e do compromisso com a melhoria contínua (FISHER et al., 2009).

\section{Indicadores do Sistema de Gestão Ambiental}

Segundo Peris-Mora et al. (2005), indicadores são instrumentos que avaliam o lado positivo ou o estado negativo do ambiente e as consequências das medidas aplicadas. Sendo assim, um indicador ambiental é um parâmetro ou o valor resultante a partir de um grupo de parâmetros que fornece informações a respeito de um fenômeno com um significado mais amplo do que aquele diretamente associado com a configuração do parâmetro.

Os indicadores de contexto ambiental estão relacionados com as condições ambientais em que uma organização está relacionada: eles podem ser aplicados em nível local, regional, nacional e em contextos globais. Eles não avaliam diretamente os impactos ambientais das atividades de uma organização, mas dão informações sobre questões ambientais que as organizações têm de enfrentar (SCIPIONI et al., 2008).

Conforme Campos, Melo e Meurer (2007), as empresas que não monitoram um conjunto de indicadores de desempenho ambiental, consequentemente, podem não estar gerenciando sua performance. Com isso, para garantir o sucesso nos resultados visando a uma maior competitividade, é de suma importância que as empresas monitorem continuamente os indicadores de desempenho ambiental.

\section{Conceituação do Sistema de Gestão de Segurança e Saúde do Trabalho}

A Organização Internacional do Trabalho (OIT) define que o objetivo do Sistema de Gestão de Segurança e Saúde no Trabalho é:

[...] proporcionar um método de avaliar e de melhorar comportamentos relativamente à prevenção de incidentes e de acidentes no local de trabalho, através da gestão efetiva de riscos perigosos e de riscos no local de trabalho. (ORGANIZAÇÃO..., 2011, p. 3).

Os autores Mendes, Silva e Medeiros (2003) afirmam que diversos sistemas de gestão foram desenvolvidos enfocando a saúde e a segurança no ambiente de trabalho com o propósito de eliminar ou minimizar os riscos de acidentes de trabalho e as condições nocivas que afetam o trabalhador, além de favorecer melhor imagem à organização diante do seu mercado consumidor.

Um sistema de gestão é formado por diversos subsistemas que devem ser permanentemente avaliados, permitindo que o retorno de informações fundamente as decisões gerenciais. Além disso, a avaliação permitirá que a empresa analise se as suas práticas de gestão estão sendo implementadas corretamente e, pelos resultados mediante os objetivos e metas traçadas, averiguar a necessidade de alterá-las ou não (ASSEITUNO, 2007).

\subsection{OHSAS 18001:2007}

As organizações podem padronizar seu SGSST por meio de normas e diretrizes, sendo que a mais conhecida e utilizada é a OHSAS 18001 (Occupational Health and Safety Assessment Serie), que visa atender às necessidades das empresas com relação ao gerenciamento de suas obrigações de segurança e saúde no trabalho.

A Norma OHSAS especifica requisitos para um SGSST, permitindo que determinada organização desenvolva e implemente uma política e objetivos que levem em consideração requisitos legais e informações sobre os riscos de SST. Pretende-se que seja aplicada a todos os tipos e portes de organizações e se adeque a diferentes condições geográficas, culturais e sociais (OCCUPATIONAL..., 2007).

O modelo de gestão adotado pela norma OHSAS 18001 é similar ao recomendado pela BS 8800 e totalmente compatível com aquele utilizado pela norma NBR ISO 14001, relativa ao SGA. As organizações devem estabelecer e assegurar que o seu SGSST que está implantado seja seguido, atendendo aos principais elementos do modelo de gestão conforme a Norma OHSAS 18001. (OCCUPATIONAL..., 2007). 
Para Franz, Amaral e Arezes (2008), no que se refere ao estabelecimento dos critérios, a OHSAS 18001 sugere que devem ser observados durante a implantação de sistemas de gestão de SST: a) o planejamento; b) a implantação e operação; e c) a verificação e ações corretivas. Sugerindo assim, que tais estratos são importantes na gestão da SST, seguindo uma sequência similar ao ciclo PDCA.

Em função da complexidade de um SGSST, das possibilidades de variação das entradas e saídas de cada processo ao longo do tempo e para o atendimento dos princípios de melhoria contínua, o planejamento das atividades de SST exige que sejam considerados diversos parâmetros organizacionais de modo a atender aos objetivos e metas propostos, como a definição dos responsáveis em executar as ações planejadas, os recursos e prazos previstos para a realização de cada meta traçada e a definição da metodologia a fim de se atingir cada meta (ASSEITUNO, 2007).

\section{Indicadores do Sistema de Gestão de Segurança e Saúde no Trabalho}

Com a utilização sistemática de indicadores de segurança do trabalho, gestores e trabalhadores adquirem uma postura proativa, de modo que as ações de segurança passam a ser focadas no controle dos riscos ao invés da análise dos acidentes (HUDSON, 2009).

É recomendado que a organização que ainda não tem um SGSST faça um diagnóstico inicial para levantar sua situação atual em relação a esta temática, dentro dos limites estabelecidos pelo escopo, cobrindo pelo menos as seguintes áreas:

- Identificação dos aspectos de SST, considerando as condições normais e anormais de operação e incluindo partidas e paradas e situações de emergência e de acidentes;

- Identificação dos requisitos legais aplicáveis e os subscritos voluntariamente pela organização;

- Exame das práticas e procedimentos de SST existentes, inclusive as associadas à aquisição e contratação de serviços;

- Avaliação das situações de emergência e acidentes ocorridos anteriormente.

\section{Método de pesquisa}

Foi realizado um estudo de caso em uma empresa de engenharia consultiva, situada na cidade de Fortaleza-CE, que presta serviços de consultoria desde 1985 e atua em diversas áreas de engenharia, principalmente naquelas associadas a projetos de infraestrutura de grande porte, abrangendo desde a elaboração dos estudos de concepção, viabilidade e projetos até o gerenciamento/supervisão da implantação das obras, trabalhando para clientes dos setores público e privado. A empresa conta com aproximadamente 115 funcionários, divididos entre o seu escritório central e a supervisão de obras. Desta forma, trabalham 50 funcionários no escritório sede da empresa, que estão distribuídos entre vários cargos, tais como assistentes administrativos, desenhistas (cadistas), engenheiros e diretores; e 65 profissionais envolvidos na supervisão de obra.

A empresa em estudo possui um Sistema Integrado de Gestão (SIG) certificado desde Junho de 2009, composto pelas seguintes normas: NBR ISO 9001:2008 (Sistemas de Gestão da Qualidade), NBR ISO 14001:2004 (Sistemas de Gestão Ambiental) e OHSAS 18001:2007 (Sistemas de Gestão de Segurança e Saúde no Trabalho). O Sistema Integrado de Gestão utiliza-se da ferramenta gerencial PDCA para promover a melhoria contínua dos seus processos organizacionais. Para fins de interesse da pesquisa, o estudo de caso realizado abrangeu o SGA e o SGSST da empresa em questão.

\subsection{Análise dos indicadores existentes na empresa}

A empresa conta atualmente com 17 indicadores para avaliar o desempenho dos seus sistemas de gestão: SGA, SGSST e Sistema de Gestão da Qualidade (SGQ). Destes indicadores, 3 (três) são do SGA e 2 (dois) do SGSST. Pode-se explicar a existência de um número menor de indicadores para o SGA e o SGSST, em relação ao SGQ, devido, provavelmente, ao ramo de atividade da empresa (Engenharia Consultiva), já que não apresenta tantos riscos aos seus colaboradores no ambiente de trabalho se comparados à construção civil, ou à indústria química. No entanto, os indicadores do SGA e SGSST merecem tanta atenção dos gestores quanto os indicadores do SGQ, devido à importância que eles possuem para o funcionamento da empresa, para a conservação e preservação do meio ambiente e para a segurança e saúde de seus trabalhadores. A seguir, ver Tabela $1 \mathrm{com}$ os indicadores do SGA e SGSST utilizados pela empresa.

Os indicadores são monitorados mensalmente, com exceção do indicador " $N^{o}$ de eventos de sensibilização para assuntos de SST" que é realizado por semestre.

$\mathrm{O}$ acompanhamento dos indicadores ambientais permite à empresa controlar seus aspectos ambientais mais significativos, buscando alternativas de reciclagem e reuso para a utilização de papel, cartucho e toner, e de redução de consumo de energia elétrica, de modo a reduzir os impactos ambientais gerados no meio ambiente. Os dados são registrados mensalmente em planilhas do Excel e são avaliados periodicamente pelos gestores para verificar se as metas estabelecidas para cada indicador estão sendo cumpridas. Caso alguma meta não esteja sendo alcançada, os gestores buscam solucionar o problema a partir do estudo 
Tabela 1. Indicadores do SGA e SGSST da empresa de engenharia consultiva.

\begin{tabular}{lcl}
\hline & $\mathbf{N}^{\mathbf{0}}$ & \multicolumn{1}{c}{ INDICADORES } \\
\hline SGA & 1 & Consumo de cartucho (funcionário/mês) \\
& 2 & Consumo de papel (funcionário/mês) \\
& 3 & Consumo de energia elétrica (funcionário/mês) \\
SGSST & 1 & $\mathrm{~N}^{\mathbf{o}}$ de afastamentos por doenças laborais \\
& 2 & $\mathrm{~N}^{\mathbf{o}}$ de eventos de sensibilização para assuntos de SST realizados por semestre \\
\hline
\end{tabular}

Fonte: Dados fornecidos pela empresa (2012).

dos dados obtidos, verificando os fatos que podem tê-lo provocado e tomando as providências cabíveis.

Enquanto isso, os indicadores do SGSST avaliam o " $\mathrm{N}^{\mathrm{o}}$ de afastamentos por doenças laborais" ocorridos na empresa, mensalmente, e o " $\mathrm{N}^{\mathrm{o}}$ de eventos de sensibilização para assuntos de SST", semestralmente. O primeiro é monitorado pelo Departamento de Pessoa, e o segundo, pelo responsável pelo SGSST. Ambos são indicadores que são facilmente mensuráveis e transmitem dados importantes aos gestores da empresa sobre este sistema de gestão.

Para que o indicador possa ter validade, é necessário que lhe sejam estabelecidas metas, pois estas mostram se os resultados da empresa estão compatíveis com o planejado previamente, verificando onde é necessário melhorar. Verificou-se que para todos os indicadores da empresa foram estabelecidas metas, que são, periodicamente, monitoradas e avaliadas pelos responsáveis pelos sistemas de gestão e pela alta direção da empresa. $\mathrm{O}$ controle dos indicadores se torna imprescindível para avaliar o funcionamento dos sistemas de gestão e para garantir o cumprimento da política da empresa que visa principalmente à melhoria contínua dos sistemas de gestão.

Depois de análise dos indicadores do SGA e SGSST existentes na empresa, concluiu-se que eles são de grande importância para a melhoria e aperfeiçoamento dos sistemas, no entanto, eles são insuficientes, pois não contemplam vários itens das normas NBR ISO 14001 e OHSAS 18001 a que estão submetidos.

\subsection{Indicadores de Desempenho Ambiental}

A sugestão dos indicadores ambientais foi feita baseando-se nos requisitos da Norma NBR ISO 14001:2004 (ASSOCIAÇÃO..., 2004a). A partir daí, verificou-se a necessidade de se estabelecer uma classificação para estruturar o sistema de indicadores sugeridos. Desta forma, na área ambiental, os indicadores foram classificados conforme a Norma NBR ISO 14031:2004 (ASSOCIAÇÃO..., 2004b) em: Indicador de Desempenho Gerencial (IDG) ou Indicador de Desempenho Operacional (IDO).

- Indicadores de Desempenho Gerencial - Fornecem informações sobre os esforços gerenciais para influenciar o desempenho ambiental de uma organização. Os esforços gerenciais para melhorar o desempenho ambiental podem incluir implementações de políticas e programas, conformidade com requisitos ou expectativas, desempenho financeiro e relações com a comunidade.

\section{- Indicadores de Desempenho} Operacional - Fornecem informações sobre o desempenho ambiental das operações de uma organização. Estas podem ser agrupadas logicamente com base nas entradas e saídas das instalações físicas e equipamentos da organização, bem como no fornecimento e distribuição.

Conforme a NBR ISO 14031 (ASSOCIAÇÃO..., 2004b), convém que a Avaliação de Desempenho Ambiental (ADA) seja apropriada ao tamanho, localização e tipo da organização, bem como a suas necessidades e prioridades. Convém que a ADA, com o uso de sistema de indicadores, apresente uma relação custo-benefício favorável para a empresa.

\subsection{Indicadores de Desempenho de SST}

Foram propostos indicadores de SST de acordo com os requisitos da Norma OHSAS 18001:2007 (OCCUPATIONAL..., 2007). A seleção dos indicadores foi realizada a partir da identificação dos aspectos essenciais ou críticos para a melhoria da gestão da segurança para as empresas de construção, sendo selecionados aqueles mais relevantes.

Verificou-se a necessidade de também se estabelecer uma classificação para estruturar o sistema de indicadores propostos para o SGSST, assim como foi feito para os indicadores do SGA, mas, nesse caso, baseando-se na metodologia utilizada por Duarte et al. (2011). Estes autores apresentaram um sistema de indicadores para gestão da SST em empresas construtoras, mas que, no entanto, também pode ser aplicado em empresas de engenharia consultiva. O sistema serve como mecanismo de avaliação das ações de prevenção dos acidentes e de diagnóstico das não conformidades relativas à legislação de SST, associando-o com medidas estatísticas de ocorrências de acidentes de trabalho. Estes indicadores fornecem 
informações essenciais para o planejamento das medidas de prevenção de acidentes.

Desta forma, os indicadores foram classificados em três grupos distintos, conforme Duarte et al. (2011): Indicadores de Prevenção (pré factum); Indicadores de Diagnóstico; e Indicadores de Acidentes (post factum).

- Indicadores de prevenção (pré factum) - são caracterizados por monitorar ações proativas que visam à prevenção dos acidentes de trabalho.

- Indicadores de diagnóstico - têm como objetivo principal a identificação e controle dos riscos de acidentes por meio da verificação do atendimento aos requisitos de legislação NR18 (Norma Regulamentadora 18: Condições e meio ambiente de trabalho na indústria da construção).

- Indicadores de acidentes (post factum) - são focados na avaliação, controle e acompanhamento dos acidentes de trabalho, associando a frequência e gravidade destes acidentes à quantificação de custos gerados. Segundo a terminologia estabelecida nas diretrizes da Organização Internacional do Trabalho (OIT), eles são considerados indicadores reativos.

\section{Resultados e discussões}

A seguir é apresentado o tratamento e a análise dos dados, a partir da aplicação da metodologia proposta, com a discussão dos resultados obtidos.

\subsection{Propostas de Indicadores de Avaliação de Desempenho Ambiental e de Avaliação de Desempenho de Segurança e Saúde no Trabalho}

De modo a complementar os dados fornecidos pelos indicadores já existentes na empresa estudada, e sugerindo melhorias para alguns destes, encontram-se, a seguir, as propostas de Indicadores Ambientais e de SST para a empresa em questão e demais empresas do ramo. Os novos indicadores também foram selecionados a partir da observação de indicadores já utilizados por empresas de outros ramos de atividades, mas que também poderiam ser utilizados por empresas de engenharia.

A proposta destes indicadores é uma resposta à carência detectada de indicadores para empresas de engenharia do ramo de projetos e consultoria em geral, pois, por se tratar de empresas que apresentam relativamente um número menor de aspectos ambientais e de SST em comparação com outras empresas, como as construtoras e indústrias químicas, a utilização de indicadores por estas empresas acaba sendo algumas vezes negligenciada.

No entanto, a utilização de indicadores para os sistemas de gestão das empresas de engenharia consultiva pode demandar mais atenção e comprometimento dos gestores do que se imagina, justamente por se tratar de empresas com baixo risco em relação aos acidentes ambientais e do trabalho $\mathrm{e}$, por esse motivo, poderem ter suas atividades negligenciadas. Os sistemas de gestão necessitam de atenção e acompanhamento dos seus gestores, independente do ramo de atividade da empresa. Todos demandam auditorias para a detecção de não conformidades, renovação de suas certificações e cumprimento de metas e objetivos.

\subsubsection{Proposta dos Indicadores de Avaliação de Desempenho Ambiental}

Foram propostos 11 Indicadores de Avaliação de Desempenho Ambiental, elaborados a partir dos requisitos da norma NBR ISO 14001:2004 (ASSOCIAÇÃO..., 2004a), e classificados segundo a norma NBR ISO 14031:2004 (ASSOCIAÇÃO..., 2004b) em duas categorias: Indicador de Desempenho Gerencial e Indicador de Desempenho Operacional.

Os indicadores foram sugeridos a partir da obediência aos requisitos da Norma ISO 14001:2004 (ASSOCIAÇÃO..., 2004a) (ver Tabela 2). Desta forma, é possível detectar problemas nos itens e propor soluções a fim de não gerar não conformidades, e confirmar o compromisso de excelência da empresa em relação aos sistemas de gestão. Cabe ressaltar que esses indicadores, analisados em conjunto, fornecem informações essenciais para o planejamento das ações voltadas ao meio ambiente, como os programas de reciclagem da empresa.

\subsubsection{Considerações sobre a medição do nível de informação dos funcionários}

Sentindo-se a necessidade de se avaliar o "Nível de Informação" dos funcionários sobre os sistemas de gestão da empresa, utilizou-se um questionário sucinto, de modo a facilitar a interpretação dos dados pelos gestores da empresa, contendo 18 questões representativas sobre os sistemas de gestão.

Destaca-se que a metodologia utilizada para verificação do nível de informação pode ser utilizada por empresas de diferentes ramos de atividades, por ser de fácil entendimento e aplicação. Lembrando que a escolha do número de questões pode variar de acordo com as características de cada empresa, tais como número de funcionários, quantidade de sistemas de gestão, ramo de atividade da empresa, dentre outros, sugere-se que o número de questões esteja entre 17 e 25.

As perguntas foram classificadas de acordo com 3 (três) temas: SGSST, SGA e Auditoria dos Sistemas de Gestão. Das 18 (dezoito) perguntas selecionadas, 
Tabela 2. Proposta de Indicadores de Desempenho Ambiental.

\begin{tabular}{|c|c|c|c|c|}
\hline $\mathbf{N}^{\mathbf{o}}$ & NORMA NBR ISO 14001:2004 & $\begin{array}{l}\text { NDICADOR } \\
\text { PROPOSTO }\end{array}$ & UNIDADE/PERÍODO & $\begin{array}{l}\text { CLASSIFICAÇÃO } \\
\text { DO INDICADOR }\end{array}$ \\
\hline 1 & 4.2 Política Ambiental & $\begin{array}{l}\text { Índice de metas } \\
\text { atingidas do SGA }\end{array}$ & $\% / A n o$ & $\mathrm{IDG}^{*}$ \\
\hline 2 & $\begin{array}{l}\text { 4.3 Planejamento 4.3.1 Aspectos } \\
\text { Ambientais }\end{array}$ & $\begin{array}{c}\text { Consumo de energia } \\
\text { elétrica }\end{array}$ & $\begin{array}{l}\mathrm{kWh} / \text { funcionário. } \\
\text { mês** }\end{array}$ & IDO $* * *$ \\
\hline 3 & $\begin{array}{l}4 \text { Implementação e operação } 4.4 .6 \\
\text { Controle operacional }\end{array}$ & Reciclagem de papel & \%/Mês & IDO \\
\hline 4 & $\begin{array}{l}4.5 \text { Verificação } 4.5 .1 \\
\text { Monitoramento e medição }\end{array}$ & $\begin{array}{l}\text { Reciclagem de } \\
\text { cartucho e toner }\end{array}$ & \%/Mês & IDO \\
\hline 5 & $\begin{array}{l}\text { 4.3 Planejamento } 4.3 .3 \text { Objetivos, } \\
\text { metas e programa(s) }\end{array}$ & $\begin{array}{l}\text { Índice de objetivos } \\
\text { atingidos do SGA }\end{array}$ & $\% / A n o$ & IDG \\
\hline 6 & $\begin{array}{l}\text { 4.4 Implementação e operação } \\
\text { 4.4.1 Recursos, funções, } \\
\text { responsabilidades, autoridades }\end{array}$ & $\begin{array}{l}\text { Custos com os } \\
\text { programas de } \\
\text { reciclagem } / \mathrm{N}^{\mathrm{o}} \mathrm{de} \\
\text { Funcionários** }\end{array}$ & $\mathrm{R} \$ /$ Ano & IDG \\
\hline 7 & $\begin{array}{l}\text { 4.3 Planejamento } 4.3 .2 \text { Requisitos } \\
\text { legais e outros } \\
\text { 4.4 Implementação e operação } \\
\text { 4.4.1 Recursos, funções, } \\
\text { responsabilidades, autoridades } \\
\text { 4.5 Verificação } 4.5 .2 \text { Avaliação do } \\
\text { atendimento a requisitos legais e } \\
\text { outros }\end{array}$ & $\begin{array}{l}\text { Índice de Custos } \\
\text { totais com o SGA/N } \\
\text { de Funcionários** }\end{array}$ & R\$/Ano & IDG \\
\hline 8 & $\begin{array}{l}\text { 4.4 Implementação e operação } \\
\text { 4.4.1 Recursos, funções, } \\
\text { responsabilidades, autoridades } \\
\text { 4.4.3 Comunicação } \\
\text { 4.4.7 Preparação e resposta a } \\
\text { emergências }\end{array}$ & $\begin{array}{l}\text { Índice de } \\
\text { treinamentos } \\
\text { ambientais }\end{array}$ & $\begin{array}{l}\text { (Horas de treinamento/ } \\
\text { funcionário)/Ano }\end{array}$ & IDG \\
\hline 9 & $\begin{array}{l}\text { 4.4 Implementação e operação } \\
\text { 4.4.2 Competência, treinamento e } \\
\text { conscientização } \\
\text { 4.4.3 Comunicação }\end{array}$ & $\begin{array}{l}\mathrm{N}^{\circ} \text { de eventos } \\
\text { ambientais }\end{array}$ & Semestre & IDO \\
\hline 10 & $\begin{array}{l}\text { 4.4 Implementação e operação } \\
\text { 4.4.2 Competência, treinamento e } \\
\text { conscientização } \\
\text { 4.5 Verificação } 4.5 .1 \\
\text { Monitoramento e medição }\end{array}$ & $\begin{array}{l}\text { Nível de Informação } \\
\text { dos funcionários**** }\end{array}$ & Ano & IDO \\
\hline 11 & $\begin{array}{l}\text { 4.5 Verificação } 4.5 .3 \text { Não } \\
\text { conformidade, ação corretiva e } \\
\text { ação preventiva } \\
\text { 4.5.4 Controle de registros } \\
\text { 4.5.5 Auditoria Interna }\end{array}$ & $\begin{array}{c}\mathrm{N}^{\mathrm{o}} \text { de não } \\
\text { conformidades }(\mathrm{NC}) \\
\text { totais do SGA }\end{array}$ & Ano & IDO \\
\hline
\end{tabular}

*Indicadores de Desempenho Gerencial (IDG). **Número médio de funcionários dentro do período considerado. ***Indicadores de Desempenho Operacional (IDO). ****A medição do indicador "Nível de Informação dos funcionários" foi realizada a partir da aplicação de um questionário aos funcionários da empresa estudada, contendo perguntas sobre os aspectos ambientais, o qual será explicado no próximo item. Fonte: as autoras (2012). 
10 (dez) são sobre o SGSST, 4 (quatro) sobre o SGA e 4 (quatro) sobre as Auditorias dos sistemas de gestão (ver Tabela 3). Neste caso, justifica-se a seleção de um número maior de perguntas sobre SGSST em relação ao SGA e à Auditoria devido à área de atuação da empresa estudada. A quantidade de perguntas selecionadas para avaliar os sistemas de gestão da empresa transmite aos seus gestores respaldo suficiente para fundamentarem futuras decisões para correções dos problemas detectados.

Sugere-se avaliar o questionário de acordo com os níveis de influência da estrutura organizacional (níveis estratégico, tático e operacional), com o objetivo de corrigir pontualmente as possíveis deficiências de informação detectadas, de modo a facilitar a análise das respostas e a tomada de decisão pelos gestores da empresa. Observando-se que outras formas de análise do questionário podem ser feitas, conforme a necessidade de cada empresa.

Para a análise dos dados, foi estabelecida uma faixa percentual de classificação, variando entre excelente, ótimo, bom, razoável e ruim, de acordo com o número de acertos obtidos pelos funcionários sobre os assuntos questionados, conforme detalhado na Tabela 4.

A seguir, são apresentadas as características de cada uma dessas faixas de classificação e as recomendações acerca das providências a serem tomadas pelos responsáveis pelos sistemas de gestão da empresa.
- Nível Excelente: Nesta categoria, estão classificadas as perguntas em que todos os funcionários da empresa demonstraram possuir conhecimento sobre o tema abordado, ou seja, houve $\mathbf{1 0 0 \%}$ de acertos.

- Nível Ótimo: Pode-se observar que as perguntas que foram classificadas com o nível de informação "Ótimo" apresentam temas que são do domínio de um número significativo de entrevistados (90\% a 99,9\%).

RECOMENDAÇÃO: Para as questões classificadas nestes níveis, a empresa deve manter o desempenho buscando continuamente melhorias.

- Nível Bom: Neste nível de informação, estão classificadas as perguntas que obtiveram um percentual considerável de acertos pelos funcionários (80\% a $\mathbf{8 9 , 9 \%})$.

RECOMENDAÇÃO: As perguntas classificadas nesta categoria começam a apresentar uma defasagem de informação pelos funcionários, começando a merecer atenção dos responsáveis.

- Nível Razoável: Estão classificadas nesta categoria as perguntas em que uma parcela considerável de funcionários apresentou dificuldades para responder sobre os assuntos questionados, obtendo de $\mathbf{5 1 \%}$ a $\mathbf{7 9 , 9 \%}$ de acertos.

Tabela 3. Perguntas para avaliar o Nível de Informação dos funcionários.

\begin{tabular}{|c|c|c|}
\hline & $\mathbf{N}^{\mathbf{0}}$ & PERGUNTAS \\
\hline \multirow{10}{*}{ 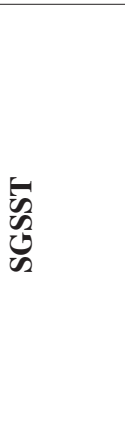 } & 1 & A que tipos de riscos você está mais sujeito no seu local de trabalho? \\
\hline & 2 & Alguma palestra informativa sobre saúde e segurança no trabalho é realizada na empresa? \\
\hline & 3 & Com que frequência estas palestras são realizadas? \\
\hline & 4 & Existe na empresa um mapa de risco? \\
\hline & 5 & Existe brigada de incêndio na sua empresa? \\
\hline & 6 & Você sabe quais os funcionários pertencentes à Brigada? \\
\hline & 7 & Existe CIPA na sua empresa? \\
\hline & 8 & Existe na sua empresa pelo menos uma rota de fuga para eventuais emergências? \\
\hline & 9 & Você saberia utilizar-se da rota de fuga caso fosse necessário? \\
\hline & 10 & Existe alguma certificação de segurança e saúde ocupacional? \\
\hline \multirow{4}{*}{$\underset{\Downarrow}{\mho}$} & 11 & Sua empresa possui alguma certificação ambiental? \\
\hline & 12 & Existe uma política ambiental estabelecida na empresa? \\
\hline & 13 & $\begin{array}{l}\text { Na empresa, é feita alguma ação voltada para a redução, reciclagem ou reaproveitamento dos } \\
\text { resíduos sólidos gerados, tais como papel, lâmpadas e pilhas? }\end{array}$ \\
\hline & 14 & $\begin{array}{l}\text { A empresa possui manual próprio que descreva os principais elementos que compõem o seu } \\
\text { sistema de gestão ambiental? }\end{array}$ \\
\hline \multirow{4}{*}{ 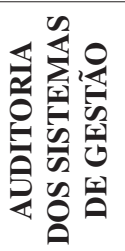 } & 15 & São realizadas auditorias internas periódicas do Sistema Integrado de Gestão? \\
\hline & 16 & Com que frequência estas auditorias são realizadas? \\
\hline & 17 & São realizadas auditorias externas periódicas do Sistema Integrado de Gestão? \\
\hline & 18 & Com que frequência estas auditorias são realizadas? \\
\hline
\end{tabular}

Fonte: as autoras (2012). 
Tabela 4. Classificação do nível de informação dos funcionários.

\begin{tabular}{cc}
\hline $\begin{array}{c}\text { CLASSIFICAÇÃO DO } \\
\text { NíVEL DE INFORMAÇÃO }\end{array}$ & PORCENTAGEM \\
\hline Excelente & $100 \%$ \\
Ótimo & $90 \%-99,9 \%$ \\
Bom & $80 \%-89,9 \%$ \\
Razoável & $50 \%-79,9 \%$ \\
Ruim & $<50 \%$ \\
\hline
\end{tabular}

Fonte: as autoras (2012).

- Nível Ruim: Considera-se que, se um determinado assunto (pergunta) é conhecido por menos de $50 \%$ dos funcionários da empresa, trata-se então de uma área considerada como "insuficiente de informação". Nesse caso, a alta direção deve priorizar os temas enquadrados nesta área, procurando corrigir a carência de informação detectada.

RECOMENDAÇÃO: Consideram-se as faixas de classificação "Razoável" e "Ruim", para efeito deste estudo, como sendo aquelas em que se enquadram as perguntas que apresentaram deficiência de informação pelos funcionários entrevistados. É necessário que a administração concentre atenção especial nessas áreas, suprindo a carência de informação dos funcionários com a adoção de medidas como treinamentos e palestras. Enfim, promovendo atividades que resolvam o problema detectado.

Ressalta-se que o objetivo da avaliação é identificar onde os funcionários estão deficientes de informação para oferecer soluções de treinamento, de acordo com as necessidades detectadas. Recomenda-se, ainda, que esta avaliação seja realizada observando-se a rotatividade dos funcionários na empresa, pois a entrada de novos funcionários irá afetar diretamente a necessidade de treinamentos sobre os sistemas de gestão.

\subsubsection{Proposta dos Indicadores de Avaliação de Desempenho de Segurança e Saúde no Trabalho}

Foram sugeridos 12 (doze) Indicadores de Avaliação de Desempenho de Segurança e Saúde no Trabalho, elaborados a partir dos requisitos da norma OHSAS 18001:2007, estando subdivididos em três grupos de indicadores, conforme proposta de Duarte et al. (2011) descrita anteriormente: Indicadores de Prevenção, Indicadores de Diagnóstico e Indicadores de Acidente (ver Tabela 5).

Com isso, os indicadores foram propostos à empresa de engenharia e, em seguida, analisados juntamente com a responsável pelos sistemas de gestão da empresa para averiguar a viabilidade de utilização. Desta forma, todos os indicadores propostos foram validados para utilização pela empresa, sendo, portanto, viáveis de serem mensurados.

\section{Conclusão}

Observou-se que a empresa controla e monitora os requisitos das normas NBR ISO 14001 e OHSAS 18001 por meio da realização periódica de auditorias (interna e externa) nos SGA e SGSST, respectivamente. As auditorias se tornam imprescindíveis, já que interferem diretamente na renovação das certificações, como também no processo de melhoria contínua dos sistemas de gestão. Observou-se, nas auditorias realizadas na empresa de engenharia consultiva, que os sistemas de gestão exigem que as empresas estejam em constante busca pela perfeição e, principalmente, por meio da observação dos pontos fracos e fortes das auditorias, a empresa conseguirá atender às exigências das legislações pertinentes, como também, às do mercado consumidor.

Constatou-se que a empresa avalia os aspectos e impactos ambientais de suas atividades como ponto inicial do processo para implantação do SGA; a partir daí é de fundamental importância que a empresa desenvolva soluções para tentar reduzir os impactos ambientais de suas atividades, pela implementação de programas ambientais para otimizar seus processos e fabricação de seus produtos, que, para este estudo específico, são os projetos de engenharia. Nesse momento, a certificação ambiental garante que a empresa vai estar constantemente avaliando e melhorando seu sistema de gestão e atendendo à legislação pertinente.

Do mesmo modo, a empresa levanta os riscos aos quais os funcionários estão submetidos no ambiente de trabalho para realizar a implantação do SGSST de modo a garantir a segurança e saúde de seus trabalhadores, atendendo às Normas Regulamentadoras (NRs) e legislações cabíveis. A certificação pela norma OHSAS 18001 é de fundamental importância para o processo de melhoria contínua do SGSST, garantindo que a empresa ofereça condições seguras e saudáveis no ambiente de trabalho para os seus funcionários.

Foram propostos 11 indicadores para o SGA e 12 para o SGSST da empresa de engenharia, considerando levantamento bibliográfico realizado inicialmente e todas as avaliações realizadas na empresa. Os indicadores propostos foram avaliados pela responsável pelos sistemas de gestão da empresa, que comprovou a viabilidade de aplicação e uso destes indicadores na empresa a partir da verificação da possibilidade de uso de cada um dos indicadores propostos com dados já existentes na empresa do ano de 2012, porém não monitorados e contabilizados como indicadores.

Verificou-se que o estabelecimento de metas para cada indicador é um fato indispensável para o seu monitoramento, pois facilita a visualização dos 
Tabela 5. Proposta de Indicadores de Desempenho de SST.

\begin{tabular}{|c|c|c|c|c|}
\hline $\mathbf{N}^{\mathbf{0}}$ & NORMA OHSAS 18001:2007 & $\begin{array}{c}\text { INDICADOR } \\
\text { PROPOSTO } \\
\end{array}$ & $\begin{array}{l}\text { UNIDADE/ } \\
\text { PERÍODO }\end{array}$ & $\begin{array}{l}\text { CLASSIFICAÇÃO } \\
\text { DO INDICADOR }\end{array}$ \\
\hline 1 & 4.2 Política de SST & $\begin{array}{l}\text { Índice de metas do } \\
\text { SGSST atingidas }\end{array}$ & $\% /$ Ano & $\begin{array}{l}\text { Indicador de } \\
\text { prevenção }\end{array}$ \\
\hline 2 & $\begin{array}{l}\text { 4.3 Planejamento } 4.3 .1 \text { Identificação } \\
\text { de perigos, avaliação de riscos e } \\
\text { determinação de controles } \\
\text { 4.4 Implementação e operação } 4.4 .6 \\
\text { Controle operacional }\end{array}$ & $\begin{array}{l}\text { Índice de avaliações } \\
\text { ergonômicas }^{1} \\
\text { (VELOSO NETO, } \\
\text { 2007) }\end{array}$ & $\% /$ Trimestre & $\begin{array}{l}\text { Indicador de } \\
\text { prevenção }\end{array}$ \\
\hline 3 & $\begin{array}{l}\text { 4.3 Planejamento } 4.3 .3 \text { Objetivos e } \\
\operatorname{programa}(\mathrm{s})\end{array}$ & $\begin{array}{l}\text { Índice de objetivos } \\
\text { atingidos do SGSST }\end{array}$ & $\% / A n o$ & $\begin{array}{l}\text { Indicador de } \\
\text { prevenção }\end{array}$ \\
\hline 4 & $\begin{array}{l}\text { 4.3 Planejamento 4.3.2 Requisitos legais } \\
\text { e outros } \\
\text { 4.4 Implementação e operação } 4.4 .1 \\
\text { Recursos, funções, responsabilidades, } \\
\text { autoridades } \\
\text { 4.5 Verificação } 4.5 .2 \text { Avaliação do } \\
\text { atendimento a requisitos legais e outros }\end{array}$ & $\begin{array}{l}\text { Índice de custos* totais } \\
\text { com o SGSST }\end{array}$ & $\% / A n o$ & $\begin{array}{l}\text { Indicador de } \\
\text { prevenção }\end{array}$ \\
\hline 5 & $\begin{array}{l}\text { 4.4 Implementação e operação } 4.4 .1 \\
\text { Recursos, funções, responsabilidades, } \\
\text { autoridades } \\
\text { 4.4.3 Comunicação, participação e consulta } \\
\text { 4.4.7 Preparação e resposta a emergências }\end{array}$ & $\begin{array}{c}\text { Índice de } \\
\text { treinamentos de SST } \\
\text { (DUARTE et al., 2011) }\end{array}$ & $\begin{array}{c}\text { (Horas de } \\
\text { treinamento/ No } \\
\text { de funcionário**) } \\
\text { / Ano }\end{array}$ & $\begin{array}{l}\text { Indicador de } \\
\text { prevenção }\end{array}$ \\
\hline 6 & $\begin{array}{l}\text { 4.4 Implementação e operação } \\
\text { 4.4.2 Competência, treinamento e } \\
\text { conscientização } \\
\text { 4.4.3 Comunicação, participação e consulta }\end{array}$ & $\begin{array}{l}\mathrm{N}^{\mathrm{o}} \text { de eventos de } \\
\text { sensibilização para } \\
\text { assuntos de SST } \\
\text { realizados }\end{array}$ & Semestre & $\begin{array}{l}\text { Indicador de } \\
\text { prevenção }\end{array}$ \\
\hline 7 & $\begin{array}{l}\text { 4.4 Implementação e operação } \\
\text { 4.4.2 Competência, treinamento e } \\
\text { conscientização } \\
\text { 4.5 Verificação } 4.5 .1 \text { Monitoramento e } \\
\text { medição do desempenho }\end{array}$ & $\begin{array}{l}\text { Nível de Informação } \\
\text { dos funcionários*** }\end{array}$ & Ano & $\begin{array}{l}\text { Indicador de } \\
\text { prevenção }\end{array}$ \\
\hline 8 & $\begin{array}{l}\text { 4.4 Implementação e operação } \\
\text { 4.4.2 Competência, treinamento e } \\
\text { conscientização }\end{array}$ & $\begin{array}{l}\text { Índice de participação } \\
\text { na SIPAT }\end{array}$ & $\% / A n o$ & $\begin{array}{l}\text { Indicador de } \\
\text { prevenção }\end{array}$ \\
\hline 9 & $\begin{array}{l}\text { 4.4 Implementação e operação } 4.4 .6 \\
\text { Controle operacional }\end{array}$ & $\begin{array}{c}\text { Índice de } \\
\text { rotatividade**** } \\
\text { (DUARTE et al., 2011) }\end{array}$ & $\% /$ Trimestre & $\begin{array}{l}\text { Indicador de } \\
\text { prevenção }\end{array}$ \\
\hline 10 & $\begin{array}{l}\text { 4.4 Implementação e operação } 4.4 .7 \\
\text { Preparação e resposta a emergências }\end{array}$ & $\begin{array}{l}\mathrm{N}^{\mathrm{o}} \text { de afastamentos por } \\
\text { doenças laborais/ } \mathrm{N}^{\mathrm{o}} \text { de } \\
\text { funcionários }\end{array}$ & $\%$ / Semestre & $\begin{array}{l}\text { Indicador de } \\
\text { acidente }\end{array}$ \\
\hline 11 & $\begin{array}{l}\text { 4.4 Implementação e operação } 4.4 .7 \\
\text { Preparação e resposta a emergências }\end{array}$ & $\begin{array}{l}\mathrm{N}^{\mathrm{o}} \text { de acidentes de } \\
\text { trabalho ocorridos } \\
\text { na empresa/ } \mathrm{N}^{\mathrm{o}} \text { de } \\
\text { funcionários }{ }^{* *}\end{array}$ & $\%$ / Semestre & $\begin{array}{l}\text { Indicador de } \\
\text { acidente }\end{array}$ \\
\hline 12 & $\begin{array}{l}\text { 4.5 Verificação } 4.5 .3 \text { Investigação de } \\
\text { incidentes, não conformidade, ação } \\
\text { corretiva e ação preventiva } \\
\text { 4.5.4 Controle de registros } \\
\text { 4.5.5 Auditoria Interna }\end{array}$ & $\begin{array}{l}\mathrm{N}^{\mathrm{o}} \text { de não } \\
\text { conformidades totais } \\
\text { do SGSST }\end{array}$ & Ano & $\begin{array}{l}\text { Indicador de } \\
\text { diagnóstico }\end{array}$ \\
\hline
\end{tabular}

${ }^{1} \mathrm{O}$ cálculo do índice de avaliações ergonômicas no ambiente de trabalho dos funcionários é feito a partir da fórmula que relaciona o número de avaliações ergonômicas realizadas pelo número de avaliações planejadas. *Investimento com a renovação da certificação de SST e com materiais indispensáveis para manter o escritório livre dos agentes de riscos ergonômicos, tais como: cadeiras e mesas adequadas para cada funcionário, apoio para os pés, sinalizadores nas escadas, etc. **Número de funcionários dentro do período considerado (média de funcionários). ***Explicado anteriormente. ****Rotatividade de pessoal, no contexto de Recursos Humanos, refere-se à relação entre admissões e demissões ou à taxa de substituição de trabalhadores antigos por novos, representado pela fórmula: [( $\mathrm{N}^{\mathrm{o}}$ de admissões $+\mathrm{N}^{\mathrm{o}}$ de demissões)/2] $/ \mathrm{N}^{\mathrm{o}}$ médio de funcionários x 100\%. Fonte: as autoras (2012). 
resultados pelos gestores e alta administração sobre o atingimento dos objetivos propostos, fornecendo dados concretos sobre o desempenho dos sistemas. A partir daí, os responsáveis poderão determinar as ações cabíveis para a correção das falhas encontradas, promovendo as melhorias necessárias nos sistemas, principalmente para os indicadores que obtiveram uma avaliação negativa, e investir em ações que corrijam as deficiências encontradas.

Os indicadores propostos podem ser empregados em SGA e SGSST de empresas que estejam no mesmo ramo de atuação da empresa estudada, como também podem ser facilmente implementados por empresas de outros ramos de atividades, como empresas comerciais e escritórios em geral, por se tratar de indicadores de fácil implementação e controle.

\section{Referências}

ASSEITUNO, M. A. Análise da importância de indicadores de desempenho da gestão da saúde e segurança no trabalho em uma empresa do ramo do agronegócio. 2007. 113 f. Dissertação (Mestrado em Gestão Integrada em Saúde do Trabalho e Meio Ambiente)-Centro Universitário SENAC, Santo Amaro, 2007.

ASSOCIAÇÃO BRASILEIRA DE NORMAS TÉCNICAS - ABNT. NBR ISO 14001: sistema de gestão ambiental: requisitos com orientações para uso. Rio de Janeiro, 2004a.

ASSOCIAÇÃO BRASILEIRA DE NORMAS TÉCNICAS - ABNT. NBR ISO 14031: gestão ambiental: avaliação de desempenho ambiental: diretrizes. Rio de Janeiro, 2004b.

CAMPOS, L. M. S.; MELO, D. A; MEURER, S. A. A importância dos indicadores de desempenho ambiental nos sistemas de gestão ambiental (SGA). In: ENCONTRO NACIONAL SOBRE GESTÃO EMPRESARIAL E MEIO AMBIENTE - ENGEMA, 9., 2007, Curitiba. Anais... Curitiba: ABEPRO, 2007.

CAMPOS, L. M. S.; SELIG, P. M. SGADA: Sistema de Gestão e Avaliação do Desempenho Ambiental: a aplicação de um modelo de SGA que utiliza o Balanced Scorecard (BSC). Revista Eletrônica de Administração, v. 8, n. 6, 2002. Edição Especial 30.

DIAS, R. Gestão ambiental: responsabilidade social e sustentabilidade. 2. ed. São Paulo: Atlas, 2011. 220 p.

DONAIRE, D. Gestão ambiental na empresa. 2. ed. São Paulo: Atlas, 2008. 169 p.

DUARTE, C. M. M. et al. Gestão de Segurança e Saúde do trabalho em empresas construtoras através de sistema de indicadores. Revista da Ciência da Administração, v. 4, p. 1-20, 2011.

FISHER, G. et al. Gestão da qualidade: segurança do trabalho e gestão ambiental. Tradução Ingeborg Sell. 2. ed. São Paulo: Blucher, 2009. 240 p.
FRANZ, L. A. S.; AMARAL, F. G.; AREZES, P. M. F. M. Modelos de Gestão da Segurança e Saúde no Trabalho: uma revisão sobre as práticas existentes e suas características, Revista Gestão Industrial, v. 4, n. 4, p. 138-154, 2008.

HUDSON, P. T. W. Process indicators: managing safety by the numbers. Safety Science, v. 47, n. 4, p. 483-485, 2009. http://dx.doi.org/10.1016/j.ssci.2008.07.037

LOZANO, M.; VALLÉS, J. An analysis of the implementation of an environmental management system in a local public administration. Journal of Environmental Management, v. 82, n. 4, p. 495-511, 2007. PMid:16632169. http://dx.doi.org/10.1016/j. jenvman.2006.01.013

MENDES, N. C. N.; SILVA, G. C. S.; MEDEIROS, D. D. Proposta de Indicadores para Sistemas de Gestão de Saúde e Segurança do Trabalho em Conformidade ao Sistema de Gestão da Qualidade. In: ENCONTRO NACIONAL DE ENGENHARIA DE PRODUÇÃO, 23., 2003. Ouro Preto. Anais... Ouro Preto: ABEPRO, 2003.

OCCUPATIONAL HEALTH \& SAFETY ADVISORY SERVICES - OHSAS. OHSAS 18001: occupational health and safety management systems: requirements. London, 2007.

ORGANIZAÇÃO INTERNACIONAL DO TRABALHO - OIT. Sistema de Gestão da Segurança e Saúde no Trabalho: um instrumento para uma melhoria contínua. Brasília, 2011. (Cartilha). Disponível: $<$ http://www.ilo.org/wcmsp5/groups/public/---ed_ protect/---protrav/---safework/documents/publication/ wcms_154878.pdf >. Acesso em: 17 jul. 2012.

OLIVEIRA, O. J.; SERRA, J. R. Benefícios e dificuldades da gestão ambiental com base na ISO $14001 \mathrm{em}$ empresas industriais de São Paulo. Produção, v. 20, n. 3, p. 429-438, 2010. http://dx.doi.org/10.1590/ S0103-65132010005000013

PERIS-MORA, E. et al. Development of a system of indicators for sustainable port management. Marine Pollution Bulletin, v. 50, n. 12, p. 1649-1660, 2005. PMid:16095626. http://dx.doi.org/10.1016/j. marpolbul.2005.06.048

SCIPIONI, A. et al. The ISO 14031 standard to guide the urban sustainability measurement process: an Italian experience. Journal of Cleaner Production, v. 16, p. 1247-1257, 2008. http://dx.doi.org/10.1016/j. jclepro.2007.06.013

SERVIÇO SOCIAL DA INDÚSTRIA - SESI. Construção e análise de indicadores. Curitiba, 2010. 108 p. (Cartilha). Disponível <http://www.eadsesipr.org.br/ead/mod/url/ view.php?id=1892>. Acesso em: 19 jul. 2012.

TACHIZAWA, T. Gestão ambiental e responsabilidade social corporativa: estratégias de negócios focadas na realidade brasileira. 7. ed. São Paulo: Atlas, 2011. 450 p.

VELOSO NETO, H. A. Novos indicadores de desempenho em matéria de higiene e segurança no trabalho: perspectivas de utilização em benchmarking. 2007. 183 f. Dissertação (Mestrado em Engenharia Humana)Universidade do Minho, Guimarães, 2007. 